\title{
STOCHASTIC MODELING AND OPTIMIZATION OF COMPLEX INFRASTRUCTURE SYSTEMS
}

\author{
P. Thoft-Christensen \\ Department of Building Technology and Structural Engineering \\ Aalborg University, Aalborg, Denmark \\ ptc@bt.aau.dk
}

\begin{abstract}
In this paper it is shown that recent progress in stochastic modeling and optimization in combination with advanced computer systems has now made it possible to improve the design and the maintenance strategies for infrastructure systems. The paper concentrates on highway networks and single large bridges. United States has perhaps the largest highway networks in the world with more than 6 million kilometers of roadway and more than 0.5 million highway bridges; see [2]. About $40 \%$ of these bridges are considered deficient and more than $\$ 50$ billion is estimated needed to correct the deficiencies; see [12]. The percentage of substandard bridges deemed to require urgent actions in other countries such as France (15\%) and UK (20\%) is also high; see [3].
\end{abstract}

Keywords: Stochastic modeling, Infrastructure systems, Bridge management systems, Suspension bridges.

\section{Introduction}

Obtaining and maintaining advanced infrastructure systems plays an important role in modern societies. Developed countries have in general well established infrastructure systems but most non-developed countries are characterized by having bad or no effective infrastructure systems. Therefore, in the transition from a non-developed country to a well developed country construction of effective infrastructure systems plays an important role. However, it is a fact that construction of new infrastructure systems requires great investments so a careful planning of all details in the system is essential for the effectiveness of the system from an operational but also economical point of view.

Obtaining the resources needed to establish infrastructure systems is only the first step. The next step and perhaps the most expensive step 
is to maintain the systems. It is recognized in most developed countries that good maintenance of infrastructure systems is in the long run the most economical way to keep the infrastructure in a satisfactory state. Effective maintenance requires however more resources than available in most countries. Therefore, careful planning of maintenance strategies is essential for all types of infrastructures.

\section{Formulation of the Cost Optimization Problem}

An infrastructure system consists of a number of structures. The objective is to minimize the cost of maintaining such a group of structures in the service life of the infrastructure. Estimation of the service life costs is a very uncertain so that a stochastic modeling is clearly needed. This can be expressed mathematically as

$$
\min E[C]=\min \left(E\left[C_{M}\right]+E\left[C_{U}\right]+E\left[C_{F}\right]\right)
$$

where

$E[C]$ is the expected total cost in the service life of the infrastructure

$E\left[C_{M}\right]$ is the expected maintenance cost in the service life of the infrastructure

$E\left[C_{U}\right]$ is the expected user costs e.g. traffic disruption costs due to works or restrictions on the structure

$E\left[C_{F}\right]$ is the expected costs due to failure of structures in the infrastructure.

For a single structure $i$ in the infrastructure the expected cost can be written

$$
\begin{aligned}
E\left[C_{i}\right] & =E\left[C_{M i}\right]+E\left[C_{U i}\right]+E\left[C_{F i}\right] \\
& =\sum_{t=1}^{T}\left\{( 1 + \gamma ) ^ { - 1 } \left[E\left[C_{M i}(t)\right] P\left(M_{i t}\right)\right.\right. \\
& \left.+E\left[C_{U i}(t)\right] P\left(U_{i t}\right)+E\left[C_{F i}(t)\right] P\left(F_{i}(t)\right]\right\}
\end{aligned}
$$

where

$\begin{array}{ll}\gamma & \text { is the discount rate (factor) e.g. } 6 \% \\ E\left[C_{i}\right] & \text { is the expected total cost for structure } i \\ E\left[C_{M i}(t)\right] & \text { is the expected maintenance cost for structure } i \text { in year } t \\ E\left[C_{U i}(t)\right] & \text { is the expected user costs for structure } i \text { in year } t \\ E\left[C_{F i}(t)\right] & \text { is the expected failure cost for structure } i \text { in year } t \\ P\left(M_{i t}\right) & \text { is the probability of the event } \\ P\left(D_{i t}\right) & \text { "maintenance is necessary" for structure } i \text { in year } t \\ P\left(F_{i t}\right) & \text { necessary" for structure } i \text { in year } t \\ T & \text { is the probability of the event "maintenance is } \\ T & \text { necessary" for structure } i \text { in year } t\end{array}$


Let the number of structures in the considered infrastructure be $m$. The expected total cost for the group can then be written

$$
\begin{aligned}
E[C] & =\sum_{i=1}^{m}\left\{E\left(C_{M i}\right)+E\left(C_{U i}\right)+E\left(C_{F i}\right)\right\} \\
& =\sum_{i=1}^{m} \sum_{t=1}^{T}\left\{( 1 + \gamma ) ^ { - 1 } \left[E\left[C_{M i}(t)\right] P\left(M_{i t}\right)\right.\right. \\
& \left.+E\left[C_{U i}(t)\right] P\left(U_{i t}\right)+E\left[C_{F i}(t)\right] P\left(F_{i}(t)\right]\right\}
\end{aligned}
$$

\section{Bridge Networks}

Future advanced bridge management systems will be based on simple models for predicting the residual strength of structural elements. Improved stochastic modeling of the deterioration is needed to be able to formulate optimal strategies for inspection and maintenance of deteriorated bridges. However, such strategies will only be useful if they are also combined with expert knowledge. It is not possible to formulate all expert experience in mathematical terms. Therefore, it is believed that future management systems will be expert systems or at least knowledgebased systems; see [15].

Methods and computer programs for determining rational inspection and maintenance strategies for concrete bridges must be developed. The optimal decision should be based on the expected benefits and total cost of inspection, repair, maintenance and complete or partial failure of the bridge. Further, the reliability has to be acceptable during the expected lifetime.

The first major research on combining stochastic modeling, expert systems and optimal strategies for maintenance of reinforced concretes structures was sponsored by EU in 1990 to 1993. The research project is entitled "Assessment of Performance and Optimal Strategies for inspection and Maintenance of Concrete Structures Using Reliability Based Expert systems". The results are presented in several reports and papers; see e.g. [15] and [5]. The methodology used in the project is analytic with traditional numerical analysis and rather advanced stochastic modeling.

Monte Carlo simulation has been used in decades to analyze complex engineering structures in many areas, e.g. in nuclear engineering. In modeling reliability profiles for reinforced concrete bridges Monte Carlo simulation seems to be used for the first time in December 1995 in the Highways Agency project "Revision of the Bridge Assessment Rules based on Whole Life Performance: Concrete" (1995-1996, Contract: DPU $9 / 3 / 44)$. The project is strongly inspired by the above- 
mentioned EU-project. The methodology used is presented in detail in the final project report, see [24].

In the Highways Agency project "Optimum Maintenance Strategies for Different Bridge Types" (1998-2000, Contract: 3/179), the simulation approach was extended in 1998, see [17] and [18] to include stochastic modeling of rehabilitation distributions and preventive and essential maintenance for reinforced concrete bridges. A similar approach is used in the project on steel/concrete composite bridges, see [6].

In a recent project "Preventive Maintenance Strategies for Bridge Groups (2001-2003, Contact 3/344 (A+B)), the simulation technique is extended further to modeling of condition profiles, and the interaction between reliability profiles and condition profiles for bridges, and the whole life costs. The simulation results are detailed presented in [7] and $[23],[22]$.

\section{Estimation of Service Life of Infrastructures}

In this paper service life assessment of infrastructures is discussed based on stochastic models and with special emphasis on deterioration of reinforced structures due to reinforcement corrosion.

The service life $T_{\text {service }}^{(1)}$ for a reinforced concrete structure has been the subject of discussion between engineers for several decades. Several authors; see e.g. [16]; have defined the service life as the initiation time for corrosion $T_{\text {corr }}$ of the reinforcement.

The service life $T_{\text {service }}^{(1)}$ has later been modified so that the time $\Delta t_{\text {crack }}$ from corrosion initiation to corrosion crack initiation in the concrete is included; see [19]. The service life is then defined by $T_{\text {service }}^{(2)}=T_{\text {crack }}=$ $T_{\text {corr }}+\Delta t_{\text {crack }}$. A stochastic model for $\Delta t_{\text {crack }}$ may be developed on the basis of existing deterministic theories for crack initiation; see [10].

The service life may further be modified so that the time $\Delta t_{\text {crack width }}$ from corrosion crack initiation to formation of a certain (critical) crack width is included; see [20]. By this modeling it is possible to estimate the reliability of a given structure on the basis of measurements of the crack widths on the surface of the concrete structure.

Corrosion initiation period refers to the time during which the passivation of steel is destroyed and the reinforcement starts corroding actively. If Ficks law of diffusion can represent the rate of chloride penetration into concrete, then it can be shown that the time $T_{\text {corr }}$ to initiation of reinforcement corrosion is

$$
T_{\text {service }}^{(1)}=T_{\text {corr }}=\frac{d^{2}}{4 D}\left(\left(\operatorname{erf}^{-1}\left(\frac{C_{c r}-C_{0}}{C_{i}-C_{0}}\right)\right)^{-2}\right.
$$


where $d$ is the concrete cover, $D$ is the diffusion coefficient, $C_{c r}$ is the critical chloride concentration at the site of the corrosion, $C_{0}$ is the equilibrium chloride concentration on the concrete surface, $C_{i}$ is the initial chloride concentration in the concrete, erf is the error function.

After corrosion initiation the rust products will initially fill the porous zone around the steel/concrete surface. As a result of this, tensile stresses are initiated in the concrete. With increasing corrosion the tensile stresses will reach a critical value and cracks will be developed. During this process the volume of the corrosion products at initial cracking of the concrete $W_{c r}$ it will occupy three volumes, namely the porous zone $W_{\text {porous }}$, the expansion of the concrete due to rust pressure $W_{\text {expan }}$, and the space of the corroded steel $W_{\text {steel }}$. With this modeling and some minor simplifications it can then be shown that the time from corrosion imitation to crack initiation is; see [10]

$$
\begin{aligned}
\Delta t_{\text {crack }} & =\frac{1}{2 \times 0.383 \times 10^{-3} D_{\text {bar }} i_{\text {corr }}} \\
& \times\left(\frac{\rho_{\text {steel }}}{\rho_{\text {steel }}-0.58 \rho_{\text {ust }}}\left(W_{\text {porous }}-W_{\text {expan }}\right)\right)^{2}
\end{aligned}
$$

where $D_{b a r}$ is the diameter of the reinforcement bar, $i_{c o r r}$ is the annual mean corrosion rate, $\rho_{\text {steel }}$ is the density of the steel, and $\rho_{\text {rust }}$ is the density of the rust products.

After formation of the initial crack the rebar cross-section is further reduced due to the continued corrosion, and the width of the crack is increased. Experiments (see e.g. [1]) show that the function between the reduction of the rebar diameter $\Delta D_{b a r}$ and the corresponding increase in crack width $\Delta w_{\text {crack }}$ in a given time interval $\Delta t$ measured on the surface of the concrete specimen can be approximated by a linear function

$$
W_{\text {crack }}=\gamma \Delta D_{b a r}
$$

where the factor $\gamma$ is of the order 1.5 to 5 . This linearization has been confirmed by FEM analyses; see [21]. Let the critical crack width be $W_{\text {critical }}$ corresponding to the service life $T_{\text {service }}^{(3)}$. By setting $T_{\text {service }}^{(3)}=$ $W_{\text {critical }}$ the following expression is obtained for $T_{\text {service }}^{(3)}$

$$
T_{\text {service }}^{(3)}=\frac{W_{\text {critical }}\left(T_{\text {crack }}\right)}{\gamma c_{\text {corr }} i_{\text {corr }}}+T_{\text {crack }}
$$

$W_{\text {crack }}\left(T_{\text {crack }}\right) \approx 0$ is the initial crack width at the time $T_{\text {crack. }}$. Using Monte Carlo simulation, the distribution functions of $T_{\text {service }}^{(1)}, T_{\text {service }}^{(2)}$ and $T_{\text {service }}^{(3)}$ can then for a given structure be estimated for any value of the critical crack width when stochastic distributions are known for all parameters. 


\section{Stochastic Modeling of Maintenance Strategies}

After a structural assessment of the reliability of a reinforced concrete bridge deck at the time $T_{0}$ the problem is to decide if the bridge deck should be repaired and, if so, how and when it should be repaired. Solution of this optimization problem requires that all future inspections and repairs are taken into account. After each structural assessment the total expected benefits minus expected repair and failure costs in the residual lifetime of the bridge are maximized considering only the repair events in the residual service life of the bridge.

In order to simplify the decision modeling it is assumed that $N_{R}$ repairs of the same type are performed in the residual service life $T_{\text {service }}$ of the bridge. The first repair is performed at the time $T_{R_{1}}$, and the remaining repairs are performed at equidistant times at the time interval $t_{R}=\left(T_{\text {service }}-T_{R_{1}}\right) / N_{R}$. This decision model can be used in an adaptive way if the model is updated after an assessment (or repair) and a new optimal repair decision is made with regard to $t_{R}$. Therefore, it is mainly the time $T_{R_{1}}$ of the first repair after an assessment, which is of importance. In order to decide which repair type is optimal after a structural assessment; the following optimization problem is considered for each repair technique, see [15]:

$$
\begin{array}{cl}
\max _{T_{R}, N_{R}} W\left(T_{R}, N_{R}\right) & =B\left(T_{R}, N_{R}\right)-C_{R}\left(T_{R}, N_{R}\right)-C_{F}\left(T_{R}, N_{R}\right) \\
\text { s.t. } & \beta^{U}\left(T_{\text {service }}, T_{R}, N_{R}\right) \geq \beta^{\min } \\
& \text { or/and } T_{\text {service }}\left(T_{R}, N_{R}\right) \geq T_{\text {service }}^{\min }
\end{array}
$$

where the optimization variables are the expected number of repairs $N_{R}$ in the residual service life and the time $T_{R}$ of the first repair. $W$ are the total expected benefits minus costs in the residual lifetime of the bridge. $B$ is the benefit. $C_{R}$ is the repair cost capitalized to the time $t=0$ in the residual service life of the bridge. $C_{F}$ are the expected failure costs capitalized to the time in the residual service life of the bridge. $T_{\text {service }}$ is the expected service life of the bridge. $\beta^{U}$ is the updated reliability index. $\beta^{\text {min }}$ is the minimum reliability index for the bridge (related to a critical element or to the total system). $T_{\text {service }}^{\min }$ is the minimum acceptable service life.

The benefits $B$ play a significant role and are modelled by

$$
B\left(T_{R}, N_{R}\right)=\sum_{i=\left[T_{0}\right]+1}^{\left[T_{\text {service }}\right]} B_{i}(1+r)^{T_{0}-T_{r e f}} \frac{1}{(1+r)^{T_{i}-T_{0}}}
$$


where $[T]$ signifies the integer part of $T$ measured in years and $B_{i}$ are the benefits in year $i$ (time interval $\left[T_{i-1}, T_{i}\right]$ ). $T_{i}$ is the time from the construction of the bridge. The $i$ th term in (9) represents the benefits from $T_{i-1}$ to $T_{i}$. The benefits in year $i$ are modelled by $B_{i}=k_{0} V\left(T_{i}\right)$ where $k_{0}$ is a factor modeling the average benefits for one vehicle passing the bridge.

The expected repair costs $C_{R}$ capitalized to the time $t=0$ are modelled by

$$
C_{R}\left(T_{R}, N_{R}\right)=\sum_{i=1}^{N_{R}}\left(1-P_{F}^{U}\left(T_{R_{i}}\right)\right) C_{R_{0}}\left(T_{R_{i}}\right) \frac{1}{(1+r)^{T_{R_{i}-T_{0}}}}
$$

$P_{F}^{U}\left(T_{R}\right)$ is the updated probability of failure in the time interval $\left.] T_{0}, T_{R}\right]$. The updating is based on a no failure event and the available inspection data at the time $T_{0}$. The factor $\left(1-P_{F}^{U}\left(T_{R_{i}}\right)\right)$ models the probability that the bridge has not failed at the time of repair. $r$ is the discount rate. $C_{R_{0}}\left(T_{R_{i}}\right)$ is the cost of repair.

The capitalized expected costs $C_{F}$ due to failure are determined by

$$
C_{F}\left(T_{R}, N_{R}\right)=\sum_{i=1}^{N_{R}+1} C_{F}\left(T_{R_{i}}\right)\left(P_{F}^{U}\left(T_{R_{i}}\right)-P_{F}^{U}\left(T_{i-1}\right)\right) \frac{1}{(1+r)^{T_{R_{i}}}}
$$

where $T_{R_{0}}=T_{0}$ is the time of the structural assessment and $T_{R_{N_{R}+1}}=$ $T_{\text {service }}$ is the expected service life. The $i$ th term in (11) represents the expected failure costs in the time interval $\left.] T_{R_{i-1}}, T_{R_{i}}\right] . C_{F}(T)$ is the cost of failure at the time $T$.

\section{Design of Long Bridges}

Several short $\operatorname{span}(<500 \mathrm{~m})$ suspension bridges collapsed due to the wind. The famous and relatively long $(854 \mathrm{~m})$ Tacoma Narrows Bridge failed in 1940. In recent years much longer bridges have been constructed. The longest suspension bridge today is the Akashi Kaikyo Bridge in Japan (main span $1991 \mathrm{~m}$ ) and the second longest is the Great Belt East Bridge in Denmark (main span $1624 \mathrm{~m}$ ). Future designs with improved girder forms, lightweight cables, and control devices may be up to $3000-5000 \mathrm{~m}$ long. For such extremely long bridges, girder stability to wind action may be a serious problem, especially when the girder depth-to-width ratio is small compared with existing long bridges.

The main dynamic problem with long suspension bridges is the aeroelastic phenomenon called flutter. Flutter oscillation of a bridge girder is a stability problem and the oscillations are perpendicular to the direction of the wind and occur when the bridge is exposed to wind velocity 
above a critical value called the flutter wind velocity $U_{c r}, U_{c r}$ decreases with decreasing stiffness and damping. Flutter is therefore a serious problem for bridges with a relatively low stiffness such as long bridges. Installation of passive and active control devices may be a solution to the girder stability problem.

Application of flaps to active control of flutter of long suspension bridges has been proposed in [11] to ensure the aerodynamic stability of slender bridge girders by attaching actively controlled flaps along the girders. The Ph.D. thesis [8] deals with wind tunnel experiments with a sectional model of a girder where the control flaps are installed as integrated parts of the leading and trailing edges of the girder. Several configurations of the flaps have been tested in a wind tunnel at Instituto Technico in Lisbon, Portugal. An analysis of a full span suspension bridge is performed in the Ph.D. thesis [9]. For the used configuration of the flaps it is shown that the flutter wind velocity $U_{c r}$ can be increased by $50 \%$ compared with a girder with no flaps.

By assuming potential flow theory, it has been shown for thin airfoils in incompressible flow that the motion-induced vertical load $L_{a e}(x, t)$ and the motion-induced moment $M_{a e}(x, t)$ on the airfoil are linear in the theoretical displacement and the torsional angle and their first and second derivatives, where $x$ is the coordinate in the direction of the bridge and $t$ is the time, see [14]. Let $y$ and $z$ be the coordinates in the direction across the bridge and in the vertical direction. A similar formulation for bridges is introduced in [13]. The aeroelastic forces $L^{\text {deck }}$ and $M^{\text {deck }}$ per unit span and for small rotations can then be written, see $[4]$ :

$$
\begin{aligned}
L_{a e}^{\text {deck }}(x, t) & =\frac{\rho U^{2} B}{2}\left[K H_{1}^{\star}(K) \frac{\dot{\nu}_{z}}{U}+K H_{2}^{\star}(K) \frac{B \dot{r}_{x}}{U}\right. \\
& \left.+K^{2} H_{3}^{\star}(K) r_{x}+K^{2} H_{4}^{\star}(K) \frac{\nu_{u}}{B}\right] \\
M_{a e}^{\text {deck }}(x, t) & =\frac{\rho U^{2} B^{2}}{2}\left[K A_{1}^{\star}(K) \frac{\dot{\nu}_{z}}{U}+K A_{2}^{\star}(K) \frac{B \dot{r}_{x}}{U}\right. \\
& \left.+K^{2} A_{3}^{\star}(K) r_{x}+K^{2} A_{4}^{\star}(K) \frac{\nu_{z}}{B}\right]
\end{aligned}
$$

where $K=B \omega / U$ is the non-dimensional reduced frequency, $B$ is the girder width, $U$ is the mean wind velocity, $\omega$ is the bridge oscillating frequency (rad.) at the wind velocity $U$, and $\rho$ is air density. $H_{i}^{\star}(K)$ and $A_{i}^{\star}(K)(i=1,2,3,4)$ are non-dimensional aerodynamic derivatives which can be estimated by wind tunnel experiments. The quantities $r_{x} \dot{\nu}_{z} / U$ and $B \dot{r}_{x} / U$ are non-dimensional, effective angles of attack. Two types of actively controlled flaps are shown in figure 1. 

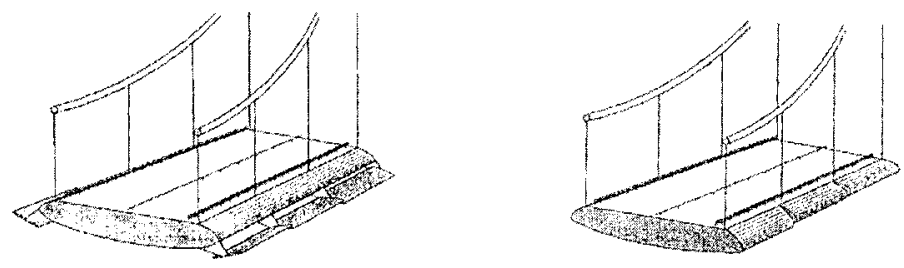

Figure 1. Sections with flaps on pylons and integrated in the section.

By assuming that the angle of a leading flap has no effect on the air circulation it can be shown that the loads due to movement of a leading flap on a thin airfoil are also linear in the angle of the leading flap and in the first and second derivatives. The motion-induced wind loads due to movement of the flaps can therefore be described by additional aerodynamic derivatives. The total motion-induced wind loads per unit

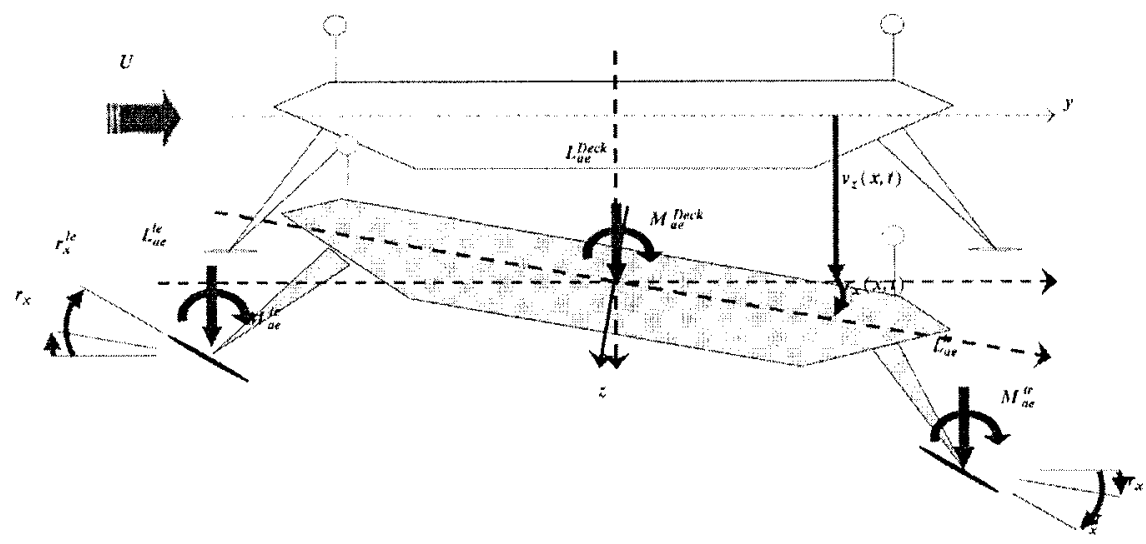

Figure 2. Motion-induced wind loads on the girder and on the flaps.

span on the girder and the flaps are, see figure 2

$$
\begin{aligned}
L_{z}^{\text {total }} & =L_{z}^{\text {deck }}+L_{z}^{t r}\left(\nu_{z}, r_{x}^{t r}\right)+L_{z}^{l e}\left(\nu_{z}, r_{x}^{l e}\right) \\
M_{x}^{\text {total }} & =M_{x}^{\text {deck }}+M_{x}^{t r}\left(\nu_{z}, r_{x}^{t r}\right)+M_{x}^{l e}\left(\nu_{z}, r_{x}^{l e}\right) \\
& +\left(L_{z}^{t r}\left(\nu, r_{x}^{t r}\right)-L_{z}^{l e}\left(-\nu, r_{z}^{l e}\right)\right) \frac{B}{2}
\end{aligned}
$$

where $\nu_{z}(x, t)$ and $r_{x}(x, t)$ are the vertical motion and the rotation of the girder at position $x$ along the bridge girder at the time $t . r_{x}^{l e}(x, t)$ and $r_{x}^{t r}(x, t)$ are the rotations of the leading and the trailing flaps. Figure 
3 shows the calculated flutter velocity $U_{c r}$ for different combinations of flap rotations. $\alpha$ is the rotation of the girder, $\alpha_{l}$ and $\alpha_{t}$ are the rotations of the leading and the trailing flaps, $\varphi_{l}$ and $\varphi_{t}$ are the phase angles between the leading flap, the trailing flap and the girder, respectively.

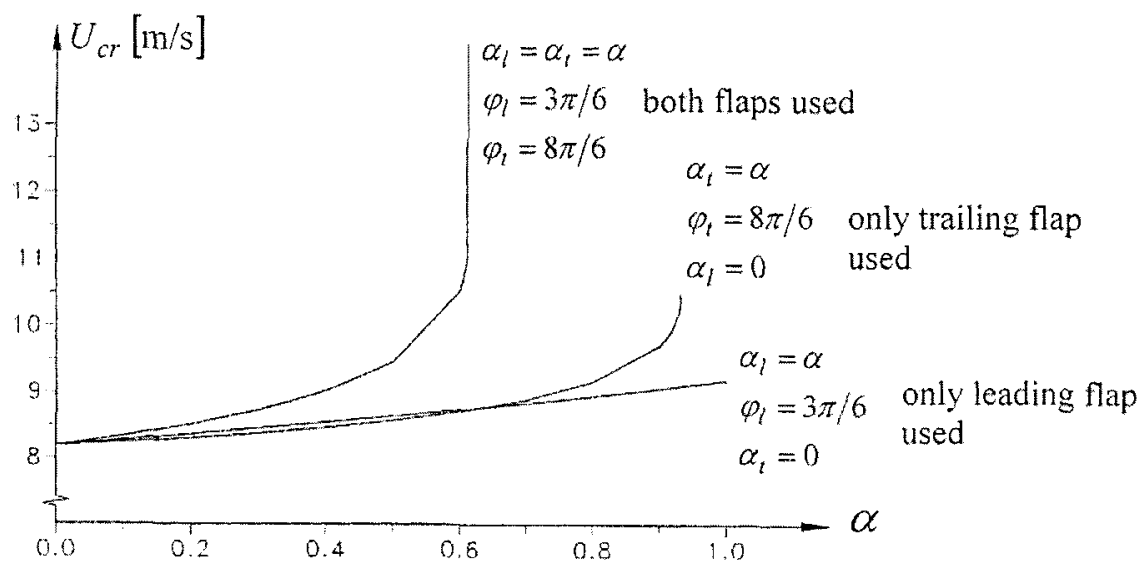

Figure 3. The theoretical effect on the flutter wind velocity of using flaps.

Figures 4 and 5 show the torsional movement of the model when the flaps are not regulated (configuration 0 ) and when they are regulated (configuration 2). The wind speed is $6.1 \mathrm{~m} / \mathrm{s}$. The conclusion is that configuration 2 is very efficient for controlling the torsional motion of the model. During the first second the torsional motion is reduced from $2.7^{\circ}$ to $1.1^{\circ}$, i.e. by $62 \%$.

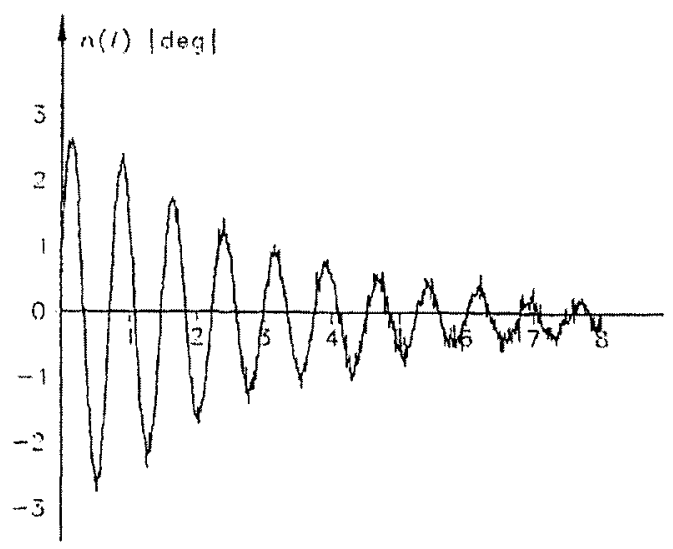

Figure 4. Torsional motion for flap configuration 0 and wind speed $6.1 \mathrm{~m} / \mathrm{s}$. 


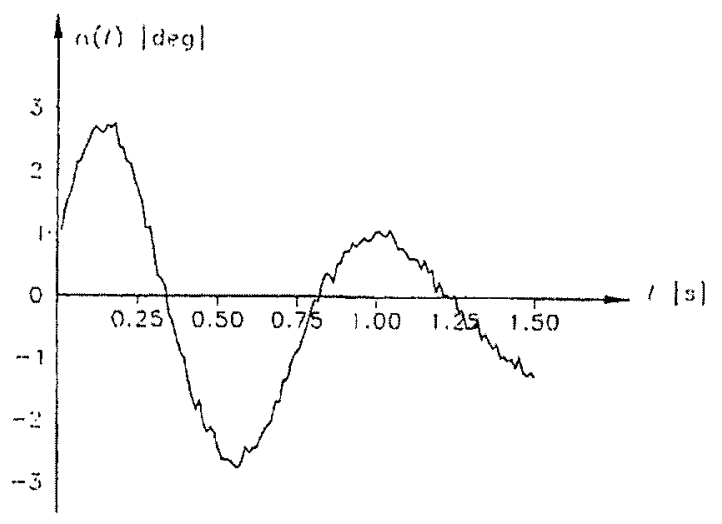

Figure 5. Torsional motion for flap configuration 2 and wind speed $6.1 \mathrm{~m} / \mathrm{s}$.

Let $\phi_{i}(x)$ and $\psi_{j}(x)$ be the vertical and the torsional mode shapes of the bridge in mode $i$ and mode $j$ which are assumed to be coupled at flutter. Then the governing modal equations for the two-mode flutter conditions are

$$
\begin{gathered}
M_{z}\left(\ddot{z}(t)+2 \omega_{z} \zeta_{z} \dot{z}(t)+\omega_{z}^{2} z(t)\right)=F_{z}^{t o t}(t) \\
M_{x}\left(\ddot{\alpha}(t)+2 \omega_{\alpha} \zeta_{\alpha} \dot{\alpha}(t)+\omega_{\alpha}^{2} \alpha(t)\right)=F_{x}^{t o t}(t)
\end{gathered}
$$

where $z(t)$ and $\alpha(t)$ are the vertical and the torsional modal coordinates. $\omega_{z}, \zeta_{z}, \omega_{\alpha}$ and $\zeta_{\alpha}$ are the natural frequencies and the damping ratios of the vertical and torsional modes. $M_{z}$ and $M_{x}$ are the vertical and the torsional modal masses. At the coupled motion, the vertical and the torsional modal responses are both assumed to be proportional to $e^{i \omega t}$, when the critical wind velocity is acting on the bridge, i.e. $z(t)=z_{0} e^{i \omega t}$ and $\alpha(t)=\alpha_{0} e^{i \omega t}$. When this is introduced into the above equations the following matrix equation can be derived

$$
\mathbf{A}\left[\begin{array}{c}
c z / B \\
\alpha
\end{array}\right]=\left[\begin{array}{l}
0 \\
0
\end{array}\right]
$$

where the system matrix $\mathbf{A}$ depends on the natural mode shapes and frequencies, the damping ratios, the derivatives and the wind velocity. This matrix equation has non-trivial solutions when

$$
\operatorname{Det}(\mathbf{A})=\operatorname{Re} \operatorname{Det}(\mathbf{A})+i \operatorname{Im} \operatorname{Det}(\mathbf{A})=0
$$


resulting in the following two flutter conditions for a bridge with separate flaps, [9]:

$$
\begin{aligned}
\operatorname{Re}(\text { Det }) & =\frac{\omega^{4}}{\omega_{z}^{4}}\left(1+\frac{M 3}{J \omega^{2} \Psi}+\frac{L 4}{m \omega^{2} \Phi}+\frac{1}{m J \omega^{4} \Psi \Phi}\right. \\
& \left.\times\left[-\omega^{2} L 1 M 2+L 4 M 3-M 4 L 3+\omega^{2} M 1 L 2\right]\right) \\
& +\frac{\omega^{3}}{\omega_{z}^{3}}\left(2 \zeta_{z} \frac{M 2}{J \omega \Psi}+2 \zeta_{\alpha} \frac{\omega_{\alpha}}{\omega_{z}} \frac{L 1}{m \omega \Phi}\right) \\
& +\frac{\omega^{2}}{\omega_{z}^{2}}\left(-1-\frac{\omega_{\alpha}^{2}}{\omega_{z}^{2}}-4 \frac{\omega_{\alpha}}{\omega_{z}} \zeta_{z} \zeta_{\alpha}-\frac{M 3}{J \omega^{2} \Psi}-\frac{\omega_{\alpha}^{2}}{\omega_{z}^{2}} \frac{L 4}{m \omega^{2} \Phi}\right) \\
& +\frac{\omega_{\alpha}^{2}}{\omega_{z}^{2}}=0 \\
\operatorname{Im}(\text { Det }) & =\frac{\omega^{3}}{\omega_{z}^{3}}\left(\frac{M 2}{J \omega \Psi}+\frac{L 1}{m \omega \Phi}+\frac{1}{m \omega^{3} \Psi J \Phi}\right. \\
& \times[L 1 M 3+L 4 M 2+M 1 L 3-M 4 L 2]) \\
& +\frac{\omega^{2}}{\omega_{z}^{2}}\left(-2 \zeta_{z}-2 \zeta_{\alpha} \frac{\omega_{\alpha}}{\omega_{z}}-2 \zeta_{\alpha} \frac{\omega_{\alpha}}{\omega_{z}} \frac{L 4}{m \omega^{2} \Phi}-2 \zeta_{z} \frac{M 3}{J \omega^{2} \Psi}\right) \\
& +\frac{\omega}{\omega_{z}}\left(-\frac{M 2}{J \omega \Psi}-\frac{\omega_{\alpha}^{2}}{\omega_{z}^{2}} \frac{L 1}{m \omega \Phi}\right)+2 \zeta_{z} \frac{\omega_{\alpha}^{2}}{\omega_{z}^{2}}+2 \zeta_{\alpha} \frac{\omega_{\alpha}}{\omega_{z}}=0
\end{aligned}
$$

where $m$ is the girder mass per unit span. $\Phi, \Xi$ and $\Psi$ are the modal integrals of the girder given by:

$$
\Psi=\int_{0}^{L} \phi_{1}^{2}(x) d x, \Xi=\int_{0}^{L} \phi_{1}(x) \psi_{1}(x) d x, \Psi=\int_{0}^{L} \psi_{1}^{2}(x) d x
$$

and where $L 1$ to $L 4$ and $M 1$ to $M 4$ contain the modal integrals of the flaps $\Phi_{f}, \Xi_{f}$ and $\Psi_{f}$, the sum of flutter derivatives referred to the girder and the flaps (see [9] for full expressions). Finally, note that the flutter mode can be a coupling of more than two modes. In that case, an additional mode gives an additional equation. The determinant condition (19) is still valid, but the calculation of the solution is rather complicated analytically. The obtained critical wind velocity $U_{c r}$ and the critical frequency $\omega_{c r}$ will not be varied by more than $5 \%$, if several similar mode shapes with close frequencies are taken into account in the flutter computation, see [9].

\section{Conclusions}

It is shown in the paper that recent developed methodologies in stochastic and optimization may be used to solve complex problems related to infrastructure systems. A general formulation of the cost optimization problem is presented with special emphasis on bridge networks. Finally, the difficult (from a formulation and mathematical point of view) 
problem of estimating the flutter wind velocity for a suspension bridge is solved numerically to show how advanced research can take part in solving infrastructure problems.

\section{References}

[1] C. Andrade, C. Alonso, and F.J. Molina. Cover cracking as a function of bar corrosion: Part 1-experimental test. Materials and Structures, 26:453-464, 1993.

[2] S.B. Chase. The bridge maintenance programme of the united states federal highway administration, 1999. In: Management of Highway Structures (Editor: P.C. Das). Thomas Telford, pp. 14-23.

[3] P.C. Das. Prioritization of bridge maintenance needs, 1999. In: Case Studies in Optimal Design and Maintenance Planning of Civil Infrastructure Systems (Editor D.M. Frangopol), ASCE, pp. 26-44.

[4] Simiu E. and R.H. Scanlan. Wind Effects on Structures: Fundamentals and Applications to Design. Third Edition. John Wiley and Sons, 1996.

[5] P. Thoft-Christensen (Editor). Assessment of performance and optimal strategies for inspection and maintenance of concrete structures using reliability based expert systems, 2002. Report. CSRconsult ApS, Aalborg, Denmark.

[6] D.M. Frangopol. Optimum maintenance strategies for different bridge types, vol. 1, steel/concrete composite bridges, 2000. Final Report, HA-project 3/179.

[7] D.M. Frangopol. Preventive maintenance strategies for bridge groups - analysis - vol.1, 2003. Final Report, HA-project 3/344(B).

[8] H.I. Hansen. Active Vibration Control of Long Suspension Bridges. PhD thesis, Aalborg University, Department of Building Technology and Structural Engineering, Aalborg, Denmark, 1998.

[9] T. Huynh. Suspension Bridge Aerodynamics and Active Vibration Control. $\mathrm{PhD}$ thesis, Aalborg University, Department of Building Technology and Structural Engineering, Aalborg, Denmark, 2000.

[10] Y. Liu and R.E. Weyers. Modelling of the time to corrosion cracking in chloride contaminated reinforced concrete structures. ACI Materials Journal, 95:675$681,1998$.

[11] K.H. Ostenfeld and A. Larsen. Bridge engineering and aerodynamics, 1992. In: Aerodynamics of Large Bridges (editor A. Larsen), Proc. First Int. Symp. Aerodynamics of Large Bridges, Copenhagen, Denmark.

[12] J.E. Roberts. Bridge management for the 21st century, 2001. In: Maintaining the Safety of Deteriorating Civil Infrastructures (Editors A. Miyamoto and D.M. Frangopol), Ube, Yamaguchi, Japan, pp. 1-13.

[13] R.H. Scanlan and J.J.Tomko. Airfoil and bridge deck flutter derivatives. J.Eng.Mech.Div., ASCE, Paper 8601:1717-1737, 1971.

[14] T. Theodorsen. General theory of aerodynamic instability and the mechanism of flutter, 1935. NACA Report No. 496.

[15] P. Thoft-Christensen. Advanced bridge management systems. Structural Engineering Review, 7:151-163, 1995.

[16] P. Thoft-Christensen. Estimation of the service lifetime of concrete bridges, 1997. In: Proc. ASCE Structures Congress XV, Portland, Oregon, USA. 
[17] P. Thoft-Christensen. Estimation of reliability distributions for reinforced concrete overbridges, 1998. HA-project 3/179, Working Document CSR-WD01.

[18] P. Thoft-Christensen. Optimum maintenance strategies for different bridge types, vol. 2, concrete bridges, 2000. Final Report, HA-project 3/179.

[19] P. Thoft-Christensen. Stochastic modelling of the crack initiation time for reinforced concrete structures, 2000. In: Proc. ASCE 2000 Structures Congress, Philadelphia.

[20] P. Thoft-Christensen. What happens with reinforced concrete structures when the reinforcement corrodes?, 2001. Keynote Speech at the 2nd International Workshop on Life-Cycle Cost Analysis and Design of Civil Infrastructure Systems, Ube, Yamaguchi, Japan. Proceedings: Maintaining the Safety of Deteriorating Civil Infrastructures, 2001, pp. 35-46.

[21] P. Thoft-Christensen. Modelling corrosion cracks, 2003. Presented at the IFIP TC-7, Conference, Sophia Antipolis, France.

[22] P. Thoft-Christensen. Preventive maintenance strategies for bridge groups- analysis - vol.2, 2003. Final Report, HA-project 3/344(B).

[23] P. Thoft-Christensen and C. Frier. Estimation of preventive maintenance costs using simulation, 2003. Report CSR-08, Aalborg, Denmark.

[24] P. Thoft-Christensen and F.M. Jensen. Revision of the bridge assessment rules based on whole life performance: Concrete, 1996. Final Report, HA-project DPU $9 / 3 / 44$. 